\title{
The Application of and Thoughts on the Online Platform Based on Lexue's 100 Big Data
}

\author{
Zezhong Yan, Shiming Ding, Xuemei Yu \\ Department of Mathematics, Zongbei Middle School, Chengdu, China \\ Email address: \\ 1156246270@qq.com (Zezhong Yan), 406158793@qq.com (Shiming Ding), 530384746@qq.com (Xuemei Yu)
}

To cite this article:

Zezhong Yan, Shiming Ding, Xuemei Yu. The Application of and Thoughts on the Online Platform Based on Lexue's 100 Big Data. Science Journal of Education. Vol. 5, No. 5, 2017, pp. 216-219. doi: 10.11648/j.sjedu.20170505.16

Received: October 10, 2017; Accepted: October 25, 2017; Published: November 15, 2017

\begin{abstract}
The educational theory of "learning before teaching and the teaching depends on learning outcomes" gained widespread popularity among teachers and students in the growth trend of the current K12 online teaching. But there are still some problems to think about such as: what students should learn before teaching, how they learn it, the effects of class preparation and so on. It is also important to know how and what teaching methods teachers should adopt in accordance with students learning. Lexue 100 has done deep study by analyzing the above-mentioned issues and worked out its own solutions. We found that with the heuristic education, systematic exercises, seasonable rewards and answering services, each student could learn from the simple to harder ones at his own pace on Lexue 100 on-line learning platform. It also shows the improvements in students' basic knowledge, skills in solving problems and interests of learning. Some experimental data will be provided. More importantly, the platform provided by Lexue 100 will combine teaching with learning greatly. "Internet plus Education" and the management of big data will make teaching, learning and supervision more rational, scientific, convenient and visual.
\end{abstract}

Keywords: Lexue 100, Learning Before Teaching, Teaching Depends on Learning Outcomes, Big Data, Intelligent Marking, Individuation

\section{Introduction}

Learning before teaching and the teaching depends on learning outcomes which is used by most teachers and it is one of the most popular teaching models in the modern teaching of primary and secondary school. This model could help students fully participate in class activities and prompt their positivity and initiatives in addition to let students play the role of principal part in learning activities as well as make the goal of three-dimensional aims included knowledge and ability, process and methods, emotional attitudes and values will be achieved.

So overall, the learning behavior of students on each step of learning activities is active. The activities of preview, presentation and feedback all depend on the individual students themselves. Consequently, the interaction makes course wonderful in the meantime the improvement will be achieved by reason of the self-learning. The basic process of this model is to assign the previewing task and check the results of the preparation then give the explanation of the common problems and lastly guide individually. Teachers have to spend much time if they want to accomplish the above missions and the learning results cannot be assured.

Moreover, In view of the problems in teaching, the author puts forward the following thoughts.

1) In the theory of learning before teaching, learning is the meaning of self-study but not aimless learning. What and how they should learn is more important.

2) Teachers should know the effects of the preview as well as the learning outcomes of students, such as the mastery and the lack of their knowledge.

3) In the theory of learning before teaching, teaching is intended to enlighten the key points for individuals but not systematic lecturing. Teaching based on the self-study courses. Teachers need to know what the key points are and what kind of instruction each particular student needs in order to ensure the effectiveness of the instruction.

4) Teachers need to receive the feedback promptly and meet the needs of the students of different academic levels and then find their weak points accurately so as to assign the individual tasks.

In this article, the author tries to offer his understandings 
and feelings about the use of Lexue 100 on-line education platform in two years and hopes the article served as a lead-in to get the guidance and suggestions from educators and colleagues.

\section{Design Proposal}

\subsection{Brief Introduction of Lexue 100}

Lexue 100 is a systematic course which designs a lot of knowledge points into a series of progressive problems by asking questions so as to make students think constantly. You can accurately grasp what students learn when they finish the whole process of learning. The course is from simple questions to complex ones which give students some solutions to learn. Secondly, Lexue 100 consists of many upgraded missions which can motivate students to some extent degree. Students can exchange the scores by completing the learning tasks into some gifts, which enhance the interest in learning. Thirdly, Students could receive "right" after finish each question if the answer is right [1]. If students cannot work out, the question-resolved system will appear "Can I help you?" that helps students deal with this question right away. Fourth: The system is intelligent for learning and teaching. The computer can make a sound judgment as long as the students start learning [2]. All the learning processes have been recorded accurately and the big data will solve the problem of what to teach as well as make precise analysis to individual differences of each student [3].

\subsection{Preparation Before Class}

\subsubsection{Preparation Before Class}

This part mainly talks about what to learn, how to learn and the learning effects before class. The mathematics courses of Lexue 100 divides the whole subject's knowledges into a lot of ten-minute learning units which are arranged with a certain order on the basis of national curriculum standards, the logic order between the knowledges and the students' cognition [4]. The structure of each unit is composed of five parts: guided learning, simple exercises, strengthening exercises, comprehensive exercises and challenging exercises. The function of guided learning is to preview. I assigned this part to students at the stage of preview with no need for any other preview tasks. Teachers do not have enough time to collect and check their homework if they assign students much preparation work. The feedback which is supported by Lexue 100 provides teachers the problems of students in the process of knowledge learning. The good news is the time which is spending on marking homework only needs five minutes at most but which cost half an hour at least before.

\subsubsection{Practices and Operations in the Class}

This paragraph mainly talks about what to teach and how to teach in the class. Giving explanations of the problems that often goes wrong according to the feedback [5]. The presentation of problems and answers that often goes wrong which is called the individual comparison teaching method makes students know the learning situation. The presentation of the right answer has served as a kind of role model for learning.

Students should review and make some strength exercises on the weak knowledges according to the statistical analysis which is offered by the computer. Doing some flexible training and the reinforcement exercises on the line at the same time. Students could sense the moving point and the transformation of different shapes in geometry vividly with the tool of the Geometer's Sketchpad.

\subsubsection{After-Class Training}

This paragraph mainly talks about how to teach according to individual differences. Since the system has shown and evaluated the training records, including mission situation, marks and so on, so I can know about them clearly. The system will recommend some exercises for promotion and contest questions for the students who do well. As for the ones who don't pass, I will ask them the reason and make different requests according to various situations. What's more, I will add some basic exercises and comprehensive ones. Students can find their mistakes in their own "Mistakes Bank" and go on exercising for one more time. That's a complete system for after-class remedy.

\subsubsection{Home-School Communication}

Parents can know about their children's learning situations. They can get these learning situations even though they are not at home as long as they connect the system to their mobile phones. Simultaneously, they can timely encourage and remind their children. Teachers are able to tell their parents students' learning situation, such as the time they spend in learning and which knowledges they have not mastered and so on.

\section{Thoughts}

1) Lexue 100 is an intelligent online education platform. In order to test its using effects, I carried out a series of learning experiments particularly by comparing the examination results of four normal classes. They are Class One, Class Two, Class Three and the Experimental Class. The Experimental Class has used Lexue 100 for a whole school year. Class one and Class Two were the classes which used Lexue 100 for only one semester and class three was the class which did not use Lexue 100. We collected the results of the entrance examination, monthly examination, mid-term examination and the final examination that showed using Lexue 100 is relevant to the academic performances. The table 1 refers to the six tests results and which shows that the academic performances would be promoted after students used Lexue 100 , and that students who used Lexue 100 did better than the ones who did not use it. In the meantime, the range has changed obviously: the longer they used the better results they got. The range of scores will grow when studying time increases.

2) In the age of big data, the tide of "Internet + Education" has been overwhelming [6]. Statistical analysis of big data 
provides us substantial information and will make teaching, learning and supervision more rational, scientific, convenient and visual. The huge amount of data from the processes of teachers' teaching and students' learning has been profoundly significant for the improvement of not only teachers' teaching but also students' learning ability [7]. Statistical analysis of big data can response comprehensively, systematically and accurately to the children's learning situation in order to help the students, parents and teachers to improve their levels of evaluation and analysis in learning, education and supervision.

3) Lexue 100 divides a great deal of long-term learning content into small units intensively. Students could use their fragments of time to learn and absorb these small learning units. Some basic knowledge is designed to game-based learning materials. It greatly improves students' learning interests and makes them love to learn. The Ranking list can be used to stimulate their passion. Students can exchange Le coins in the game into presents. This is an alluring way to let students learn incessantly. Students will make progress greatly when they hear the sound of "true". Failure is the mother of success.

4) The diversity of mathematical learning platform level achieves individual learning for students and individual teaching for teachers. Mistakes in learning of each student helps flipped teaching and layered teaching come true. Material recombination, learning materials for improving the lack of knowledge can be promptly recombined into personalized learning content according to accurate analysis of data [8]. The whole course is a highly individual system for learning and exercising by layered teaching and material recombination.

5) The system can be used to reduce teachers' repeated work by means of intelligent checking scientific statistics and automatically collecting students' mistakes [9]. It can be predicated that teachers' urgent requests include intelligent checking, statistical analysis and individual instructions [10]. For example, it is generally needs two hours to correct math homework for fifty students in one class. It is a difficult, tiring, inefficient and mechanical task. Big data and artificial intelligence will finish checking in five minutes and offer a comprehensive and scientific statistics through the online platform of Lexue 100 intelligently. It is a marvelous invention and it could reduce heavy burdens of teachers tremendously.

6) Educational professionalism and good service of Lexue 100 makes many benefits for students, teachers and parents. Through comparing accomplishments between experimental class and normal class for a year and a half makes me firmly believe that intelligence checking and statistical analysis and individual instructions will be the mathematical educational direction.

7) Education is never a simple thing because it is not just a simple presentation of a knowledge point. We should take psychology and pedagogy into consideration to improve our learning process. The simple things we have learned before become more diversified. With the development of the times, the educational media and tools are more intelligent and convenient. Lexue 100 is designed in the background of the Internet information and has much room for improvement. Learning is also a long-term process but not a tool of prediction by a few tests. Teachers undertake a large number of teaching tasks but what they want is to develop students into self-initiative learners at last. There are still a lot of problems is worthy of our studying and researching.

Table 1. Scores of regular classes and experimental class (Grade 1).

\begin{tabular}{|c|c|c|c|c|c|c|c|}
\hline Classes & $\begin{array}{l}\text { Entrance } \\
\text { examination of } \\
\text { the } 1^{\text {st }} \text { semester }\end{array}$ & $\begin{array}{l}\text { Mid-term } \\
\text { examination of } \\
\text { the } 1^{\text {st }} \text { semester }\end{array}$ & $\begin{array}{l}\text { Monthly } \\
\text { examination of } \\
\text { December }\end{array}$ & $\begin{array}{l}\text { Final } \\
\text { examination of } \\
\text { the } 1^{\text {st }} \text { semester }\end{array}$ & $\begin{array}{l}\text { Mid-term } \\
\text { examination of } \\
\text { the } 2^{\text {nd }} \text { semester }\end{array}$ & $\begin{array}{l}\text { Final } \\
\text { examination of } \\
\text { the } 2^{\text {nd }} \text { semester }\end{array}$ & $\begin{array}{l}\text { Usage time of } \\
\text { Lexue } 100 \\
\text { (semester) }\end{array}$ \\
\hline Regular Class One & 110.5 & 88.9 & 79 & 102.2 & 86.9 & 91.3 & 1 \\
\hline Regular Class Two & 110.7 & 88.2 & 77.1 & 99.2 & 84.4 & 91.6 & 1 \\
\hline Regular Class Three & 110 & 89.3 & 78.1 & 99.2 & 88.9 & 85.6 & 0 \\
\hline Experimental Class & 108 & 92.6 & 83.3 & 106.3 & 92.3 & 96.6 & 2 \\
\hline Range & -2.5 & 4.4 & 6.2 & 7.1 & 7.9 & 11 & \\
\hline
\end{tabular}

\section{Conclusion}

The Internet provides a variety of service and has changed the way of our life. The "Internet + Education" is not only a technology but also a way of learning. In the background of the large data age, people try to use it to help us to learn and understand the knowledge. We could collect enormous data when students start to learn on the platform. Large amount of data can be collected by teachers through efficient and professional education cloud platform, which will be accumulated, analyzed and applied further. From the view of the students' learning, the application of big data definitely has obvious influence on improving their learning.

The teachers, who are teaching in class, are not technicians. It can greatly liberate teachers themselves with the integration of information technology into teaching. Although there will be a tough process at the very beginning, teachers are supposed to be patient and do some experiments. They should keep pace with the times by upgrading themselves through learning and applying technology. The intelligence checking system and individual instruction is the most urgent thing for the teachers. That can be realized from the following aspects:

First, Lexue 100 provides teachers a method and a tool of intelligent evaluation. It can find out students' problems, which refer to many aspects such as basic knowledge, skills, procedural skill and so on by "Artificial Intelligence Checking System".

Second, the system can collect and analyze the learning data and organize these learning materials accurately according to the lack of knowledge for each student.

Third, individualized learning is the best design of this system. Students finish the online personalized learning material on time, 
which can be examined directly by teachers and parents to make sure if students have already understood and grasped.

Last, incentive evaluation is one of the effective ways to stimulate the interest of students learning. The game-based learning material gives students the chance of showing their talents and makes them enjoy learning process and passing barriers.

This system can not only reduce teachers' burden but also meet students' demand of personalized guidance, which is an excellent learning system. We are expecting that teachers needn't check homework manually and force students to correct mistakes one by one any more, and students' learning can become easier and more effective.

\section{References}

[1] Jiyou Jia (2017). Using data-mining technology to facilitate educational management in the era of artificial intelligence. Journal of Information Education 2017 (7): 1-2.

[2] Jiyou Jia, Yueyang Yu. (2017). Analyzing Learning Activity Index and Online Learning Activity Index. Chinese Distance Education. 2017 (4): 15-2+56.

[3] Jiyou Jia, Bilan Zhang, Zezhong Yan, Jun Ren, Baogui Cheng. (2017). The design of a web-based mathematics instruction system and its application effect in school teaching and learning. Chinese Distance Education. 2017 (3): 37-44.
[4] Jiyou Jia, Yuhao Chen, Zhuhui Ding, Yin Bai, Baijie Yang, Mei Li, Ju Qi. (2013). Effects of an intelligent web-based English instruction system on students' academic performance. Journal of Computer Assisted Learning. 29 (6): 556-568.

[5] Jiyou Jia, Yuhao Chen, Zhuhui Ding, Yin Bai, Baijie Yang, Mei Li, Ju Qi. (2013). Effects of an intelligent web-based English instruction system on students' academic performance. Journal of Computer Assisted Learning. 29 (6): 556-568.

[6] Hartley S. (1978) Meta-analysis of the effects of individually paced instruction in mathematics [D]. Dissertation Abstracts International, 38, 4003.

[7] Steenbergen-Hu, S., \& Cooper, H. (2013). A meta-analysis of the effectiveness of intelligent tutoring systems on $\mathrm{K}-12$ students' mathematical learning. Journal of Educational Psychology, 105, 970-987.

[8] Jiyou Jia, Bilan Zhang, Zezhong Yan, Jun Ren. (2017). Research on the Online Mathematics Teaching System and Its Application Effect. Distance Education. 2017 (3): 37-44+80.

[9] Cheung, A. C. K. \& Slavin, R. E. (2013). The effectiveness of educational technology applications for enhancing mathematics achievement in K-12 classrooms: A meta-analysis [J]. Educational Research Review, 9, 88-113.

[10] Koedinger, K. R., Anderson, J. R., Hadley, W. H., \& Mark, M. A. (1997). Intelligent tutoring goes to school in the big city. International Journal of Artificial Intelligence in Education, 8, 30-43. 